\title{
Calcineurin Triggers Reactive/Inflammatory Processes in Astrocytes and Is Upregulated in Aging and Alzheimer's Models
}

\author{
Christopher M. Norris, ${ }^{1}$ Inga Kadish, ${ }^{2}$ Eric M. Blalock, ${ }^{1}$ Kuey-Chu Chen, ${ }^{1}$ Veronique Thibault, ${ }^{1}$ Nada M. Porter, ${ }^{1}$ \\ Philip W. Landfield, ${ }^{1}$ and Susan D. Kraner ${ }^{1}$ \\ ${ }^{1}$ Molecular and Biomedical Pharmacology, University of Kentucky, Lexington, Kentucky 40536, and ${ }^{2}$ Cell Biology, University of Alabama, Birmingham, \\ Alabama 35294
}

Astrocyte reactivity (i.e., activation) and associated neuroinflammation are increasingly thought to contribute to neurodegenerative disease. However, the mechanisms that trigger astrocyte activation are poorly understood. Here, we studied the $\mathrm{Ca}^{2+}$-dependent phosphatase calcineurin, which regulates inflammatory signaling pathways in immune cells, for a role in astrogliosis and brain neuroinflammation. Adenoviral transfer of activated calcineurin to primary rat hippocampal cultures resulted in pronounced thickening of astrocyte somata and processes compared with uninfected or virus control cultures, closely mimicking the activated hypertrophic phenotype. This effect was blocked by the calcineurin inhibitor cyclosporin A. Parallel microarray studies, validated by extensive statistical analyses, showed that calcineurin overexpression also induced genes and cellular pathways representing most major markers associated with astrocyte activation and recapitulated numerous changes in gene expression found previously in the hippocampus of normally aging rats or in Alzheimer's disease (AD). No genomic or morphologic evidence of apoptosis or damage to neurons was seen, indicating that the calcineurin effect was mediated by direct actions on astrocytes. Moreover, immunocytochemical studies of the hippocampus/neocortex in normal aging and AD model mice revealed intense calcineurin immunostaining that was highly selective for activated astrocytes. Together, these studies show that calcineurin overexpression is sufficient to trigger essentially the full genomic and phenotypic profiles associated with astrocyte activation and that hypertrophic astrocytes in aging and AD models exhibit dramatic upregulation of calcineurin. Thus, the data identify calcineurin upregulation in astrocytes as a novel candidate for an intracellular trigger of astrogliosis, particularly in aging and AD brain.

Key words: $\mathrm{Ca}^{2+}$ regulation; hypertrophy; microarray; phosphatase; reactive; glia

\section{Introduction}

Many forms of injury or disease activate astrocytes and microglia in the CNS. Although activated glia are closely associated with amyloid plaques in Alzheimer's disease (AD) (Griffin et al., 1989; Wisniewski and Wegiel, 1991; Van Eldik and Griffin, 1994) and in mouse models of AD (Matsuoka et al., 2001; Gordon et al., 2002), activated glia also increase substantially in the hippocampus and neocortex as a function of normal aging (Wisniewski and Terry, 1973; Vaughan and Peters, 1974; Landfield et al., 1980; Finch, 2003). The activated phenotype of astrocytes is characterized by hypertrophy of the soma and processes and by an upregulation of intermediate filaments [glial fibrillary acidic protein (GFAP), vimentin (Vim)], inflammatory/immune/oxidative stress markers, extracellular matrix (ECM) molecules, and

Received Jan. 26, 2005; revised March 31, 2005; accepted April 1, 2005

This work was supported by National Institute on Aging Grants AG04542 and P01-AG10836 (P.W.L.), AG24190 (C.M.N.), and AG020251 (N.M.P.) and National Institute of Arthritis and Musculoskeletal and Skin Diseases Grant AR46477 (S.D.K.). We thank Drs. Jeffrey Molkentin and Rita Balice-Gordon for generously providing the Ad-aCaN and Ad-LacZ constructs, respectively.

Correspondence should be addressed to Christopher M. Norris, University of Kentucky College of Medicine, 131 Sanders-Brown Building, 800 South Limestone Street, Lexington, KY 40536. E-mail: cnorr2@uky.edu. D01:10.1523/JNEUROSCI.0365-05.2005

Copyright $\odot 2005$ Society for Neuroscience $\quad$ 0270-6474/05/254649-10\$15.00/0 growth factors and cytokines (Eddleston and Mucke, 1993; Ridet et al., 1997; Labourdette and Eclancher, 2002). The latter include the important neurotrophic cytokine $S 100$ calcium-binding protein, $\beta$ subunit ( $\mathrm{S} 100 \mathrm{~B})$, which can induce oxidative stress pathways (Lam et al., 2001) and $\beta$-amyloid production by dystrophic neurites (Mrak and Griffin, 2001).

Activated astrocytes are thought to provide support for damaged neural tissues through several mechanisms, including release of neurotrophic factors and degradation of amyloid deposits (Eddleston and Mucke, 1993; Ridet et al., 1997; Labourdette and Eclancher, 2002; Wyss-Coray and Mucke, 2002). In contrast, there is also mounting evidence that the inflammatory processes and unfavorable ECM changes associated with astrocyte activation contribute to age-related neurodegenerative disorders (Rogers et al., 1996; Mrak and Griffin, 2001; Finch et al., 2002; WyssCoray and Mucke, 2002; Wenk, 2003) and to dysfunction in normal brain aging (Mrak et al., 1997; Lee et al., 2000; Gemma et al., 2002).

Despite the increasingly wide recognition of the functional importance of astrocyte activation, its regulation is still poorly understood. Several extracellular factors and cytokines originating from astrocytes or other cell types have been shown to act on astrocytes in autocrine or paracrine modes [e.g., $\beta$-amyloid, 
interleukin-1, S100B, transforming growth factor $\beta$ (TGF $\beta$ ), and others] and induce components of the activated phenotype (Wyss-Coray et al., 1995; Sheng et al., 1996; Mrak and Griffin, 2001). However, the intracellular mechanisms that transduce extracellular signals and trigger programs for astrocyte activation are unclear.

One molecule that could play an important role in this intracellular signaling cascade is the $\mathrm{Ca}^{2+} /$ calmodulin-dependent protein phosphatase calcineurin, which upregulates numerous cytokines and proinflammatory factors in immune cells (Crabtree and Olson, 2002). Pathological hypertrophic reactions in cardiomyocytes also critically depend on calcineurin activation (Molkentin et al., 1998). In addition, neuronal $\mathrm{Ca}^{2+}$ regulation and signaling are changed in brain aging and models of $\mathrm{AD}$ (Landfield et al., 1989; Disterhoft et al., 1994; Foster and Norris, 1997; Thibault et al., 1998; Leissring et al., 2000; Mattson et al., 2000; Toescu et al., 2004), potentially resulting in elevated $\mathrm{Ca}^{2+}$ transients that might alter calcineurin activity.

Nevertheless, it is not yet clear what role, if any, calcineurin plays in $\mathrm{Ca}^{2+}$ signaling in astrocytes. In normal brain, calcineurin is expressed primarily in neurons and only weakly or not at all in astrocytes (Goto et al., 1986; Dawson et al., 1994). In addition, one study of immunosuppressant inhibitors of calcineurin found that they protected astrocytes from apoptosis (Matsuda et al., 1998), whereas another found the converse that calcineurin inhibitors increased apoptosis of activated astrocytes. The latter result suggests that calcineurin activity might promote maintenance or survival of activated astrocytes (Pyrzynska et al., 2001) but does not address whether increased calcineurin activity is sufficient to induce survival pathways or trigger astrocyte activation.

Here, we tested predictions of the hypothesis that calcineurin upregulation plays a causative role in orchestrating astrocyte activation. The results provide the first evidence that overexpression of calcineurin in astrocytes is sufficient for inducing the activated/inflammatory transcriptome and phenotype and, moreover, that calcineurin upregulation is present selectively in activated astrocytes of normal aging and AD model brain.

\section{Materials and Methods}

Animals and primary hippocampal cultures. Adult male wild-type (WT) $\mathrm{C} 57 \mathrm{BL} / 6 \mathrm{~J}$ and amyloid precursor protein and presenilin1 (APP/PS1) double-transgenic ( $\mathrm{Tg}$ ) mice were used in the present study for immunocytochemistry. Double-transgenic mice were generated from matings between APPswe mice and human PS1-A246E mice (Borchelt et al., 1997). These animals harbor the Swedish mutation of the amyloid precursor protein and the human familial Alzheimer's disease A246E presenilin 1 variant. Heterogeneous primary hippocampal cell cultures, which contained neurons and astroglia but essentially no oligodendrocytes or microglia, were prepared from fetal pup tissue (embryonic day 18) obtained from pregnant Fischer 344 rats as described previously (Porter et al., 1997). All experiments were conducted on cultures between 12 and $14 \mathrm{~d}$ in vitro (DIV), because neuronal polarity and synaptic connectivity is well established at this time point (Porter et al., 1997). All animal protocols were in accordance with the National Institutes of Health Guide for Care and Use of Laboratory Animals and were approved by our Institutional Animal Care and Use Committees.

Recombinant adenovirus. A calcineurin fragment lacking part of its $\mathrm{C}$ terminus and a crucial autoinhibitory domain (Hashimoto et al., 1990) was overexpressed in hippocampal cultures using an adenoviral vector (Ad-aCaN; kind gift from Dr. Jeff Molkentin, University of Cincinnati, Cincinnati, $\mathrm{OH}$ ). This calcineurin fragment exhibits catalytic activity even when $\mathrm{Ca}^{2+}$ levels are very low (Manalan and Klee, 1983). An adenoviral vector encoding $\beta$-galactosidase and internal ribosome entry sequence-green fluorescent protein (Ad-LacZ) was used to control for nonspecific adenoviral-mediated effects (Gonzalez et al., 1999) (kind gift from Dr. Rita Balice-Gordon, University of Pennsylvania, Philadelphia, $\mathrm{PA})$. All adenoviral gene products were driven by a cytomegalovirus promoter. Viruses were titered using the Adeno-X Rapid Titer kit (BD Biosciences, Franklin Lake, NJ) and added to cell cultures at a multiplicity of infection of $\leq 100$.

Fluorescent labeling of astrocytes in rat primary hippocampal cultures. At $48 \mathrm{~h}$ after treatment with Ad-aCaN or Ad-LacZ, cultures were fixed in $4 \%$ paraformaldehyde for $20 \mathrm{~min}$ and washed three times with PBS. Triton X-100 $(0.1 \%)$ was then used to permeabilize cells $(15 \mathrm{~min})$ followed by three washes with PBS. After a 30 min blocking step [in $4 \%$ bovine serum albumin (BSA) in PBS], cells were incubated overnight at $4^{\circ} \mathrm{C}$ in primary antibody diluted in 4\% BSA/PBS. Rat anti-GFAP (1:500; Zymed Laboratory, South San Francisco, CA) was used to specifically label astroglial cells, and anti-calcineurin (1:250; Chemicon, Temecula, CA) was used to label the catalytic subunit of calcineurin (calcineurin $\mathrm{A} \alpha$ ). Antibody dilutions fell within the linear detection range as established in our laboratory using hippocampal culture tissue. Western blot analysis of hippocampal cultures and hippocampal tissue from adult and aged rats shows that the Chemicon anti-calcineurin antibody identifies a band of $\sim 60 \mathrm{kDa}$, which represents the full-length calcineurin A subunit and a smaller, $<20 \mathrm{kDa}$, band that has been characterized previously and thought to be an alternate splice variant of calcineurin $A \alpha$ (Reuter et al., 2001) (see Fig. 2G). Because this antibody recognizes the N-terminal region of calcineurin $\mathrm{A}$, it also identifies the truncated $\sim 45 \mathrm{kDa}$ calcineurin fragment encoded by Ad-aCaN (see Fig. 2G). Cultures were then washed an additional three times in PBS and incubated in the dark at room temperature in secondary antibody conjugated with green ( $\mathrm{Al}-$ exa Fluor 488) or red (Alexa Fluor 594) fluorescent dye (Molecular Probes, Eugene, OR). Fluorescently labeled cells were visualized using a Nikon (Tokyo, Japan) Eclipse TE200 inverted microscope with appropriate filters. In all cases, cellular fields were chosen randomly under phase contrast conditions, in which astrocytes essentially are not visible. After an image of that field was acquired, its corresponding astrocyte profile was imaged using fluorescent filters.

Hippocampal RNA processing and Affymetrix GeneChip analysis. Hippocampal cultures were lysed in $400 \mu$ l of TRIzol reagent for RNA isolation, as described previously (Blalock et al., 2003). RNA samples were stored at $-80^{\circ} \mathrm{C}$ until further use. Each RNA sample comprised a pool of two culture dishes, and seven to nine samples were used for each experimental treatment group (i.e., uninfected, Ad-aCaN, and Ad-LacZ). Each sample was applied to its own Affymetrix (Santa Clara, CA) GeneChip (rat RG-U34A; total, $n=23$ separate chips). Chips were then processed and scanned in an Agilent (Palo Alto, CA) Affymetrix GeneArray scanner. Microarray suite (MAS) software (version 5.0; Affymetrix) was used to determine signal intensity (expression level) and presence/absence calls. These data for all arrays were copied from the MAS pivot table to an Excel 9.0 (SR1; Microsoft, Redmond, WA) workbook. Data transformations, filtering, and most statistical analyses were performed within Excel (Blalock et al., 2003), and raw data (.cel files, signal intensity values, and presence calls) can be accessed at the gene expression omnibus website under accession number GSE1978 (www.ncbi.nlm.nih.gov/geo/).

Immunohistochemical staining of mouse brain sections. At 3, 12, and 18 months of age, mice were anesthetized and transcardially perfused with $50 \mathrm{ml}$ of buffered saline, followed by $100 \mathrm{ml}$ of a $4 \%$ buffered, $\mathrm{pH} 7.4$, paraformaldehyde solution to which $0.5 \%$ picric acid was added. The brains were removed from the skull and stored in the fixative for $4 \mathrm{~h}$; thereafter, they were transferred to a $30 \%$ sucrose solution. Six series of coronal sections $(35 \mu \mathrm{m})$ were cut on a freezing microtome. Immunohistochemical procedures were similar to those described previously (Kadish et al., 2002). Briefly, the first series of sections was mounted on gelatin-coated slides and immediately stained with cresyl violet and coverslipped. The second series was immunohistochemically stained for calcineurin and the third series for GFAP. Sections were rinsed overnight in a solution of Tris-buffered saline (TBS) and treated for $30 \mathrm{~min}$ in a heated $\left(85^{\circ} \mathrm{C}\right) \mathrm{Na}$ citrate solution $(0.05 \mathrm{M}, \mathrm{pH} 6.0)$. After cooling and rinsing, the series of sections was transferred to a solution containing the primary antibody rabbit anti-calcineurin (1:500; Chemicon). This solution consisted of TBS with $0.5 \%$ Triton X-100 added (TBS-T). After incubation 
(18 $\mathrm{h}$ on a shaker table at room temperature in the dark), the sections were rinsed three times in TBS-T and transferred to a solution containing secondary antibody (goat anti-rabbit HRP, 1:400; Abcam, Cambridge, MA) for $2 \mathrm{~h}$. Sections then were rinsed three times with TBS-T and incubated for 3 min with Ni-enhanced DAB. For double staining of calcineurin and GFAP after incubating in primary antibodies, sections were rinsed and incubated in Alexa Fluor 488 goat anti-rabbit (1:100) and Texas Red avidin (1:50; Molecular Probes) for $2 \mathrm{~h}$. The stained sections were mounted on gelatinized slides and coverslipped.

\section{Results}

Active calcineurin recapitulated the hypertrophic phenotype We tested whether adenoviral-mediated transfer of an active calcineurin isoform into primary hippocampal cultures is sufficient to mimic essentially the full pattern of the astrocyte activation response of aging. Mixed, rather than pure astrocyte cultures were used to more closely approximate in vivo conditions. Under our conditions (Porter et al., 1997), the cultures primarily contain neurons and astrocytes but no oligodendrocytes or microglia (Xie et al., 2000).

At 12 DIV, hippocampal cultures were treated with a recombinant adenovirus construct encoding a truncated $(\sim 45 \mathrm{kDa})$ "active" calcineurin fragment $(\mathrm{Ad}-\mathrm{aCaN})$ or with a recombinant control adenovirus expressing $\beta$-galactosidase (Ad-LacZ). Other parallel control cultures were untreated or cotreated with a calcineurin inhibitor. After $48 \mathrm{~h}$ of exposure to these conditions, cultures were fixed and labeled immunofluorescently for GFAP, and astrocyte morphology was quantified using MetaMorph software. Western blot analysis confirmed the expression of the truncated active calcineurin subunit only in Ad-aCaN-infected cultures (see Fig. 2G). Moreover, control studies showed that cultures treated with $\mathrm{Ad}-\mathrm{aCaN}$ alone exhibited substantially greater calcineurin phosphatase activity, as determined with a standard phosphatase assay system (Bio-Rad, Hercules, CA) or with a nuclear factor of activated $\mathrm{T}$ cells (NFAT) luciferase reporter assay, than cultures in any of the other three conditions (data not shown).

A major increase in the thickness and ramification of astrocyte processes and the diameter of astrocyte somata was readily apparent in all Ad-aCaN-treated cultures relative to uninfected or Ad-LacZ control cultures $(n=9$ culture dishes per condition in at least two independent experiments) (Fig. 1). Concurrent treatment with the calcineurin inhibitor cyclosporin A (5 $\mu \mathrm{M})$ completely blocked the Ad-aCaN-induced changes (Fig. 1D). These qualitative changes were confirmed quantitatively using the Integrated Morphometry Analysis feature of the MetaMorph imaging system. An ANOVA revealed a significant difference in fiber breadth across treatment groups $(p<0.01)$, reflecting an overall increase in astrocyte size for the Ad-aCaN-treated cultures compared with both the Ad-LacZ and Ad-aCaN plus CsA groups ( $p<0.05$; Scheffé's post hoc test; data not shown). Thus, the in vitro hypertrophy and ramification induced by $\mathrm{Ad}-\mathrm{aCaN}$ mimic remarkably closely the morphologic changes found in activated astrocytes in vivo, supporting the conclusion that calcineurin overexpression is sufficient to recapitulate the hypertrophic phenotype of astrocytes seen in aged or AD brain.

\section{Expression and direct actions of active calcineurin in treated astrocytes}

One potential confound could arise if Ad-aCaN was exerting its effect on astrocytes indirectly by inducing damage in neurons that then release cytokines and activate astrocytes. For example, overexpression of calcineurin in neurons has been reported to induce neuronal apoptosis (Wang et al., 1999). However, in our
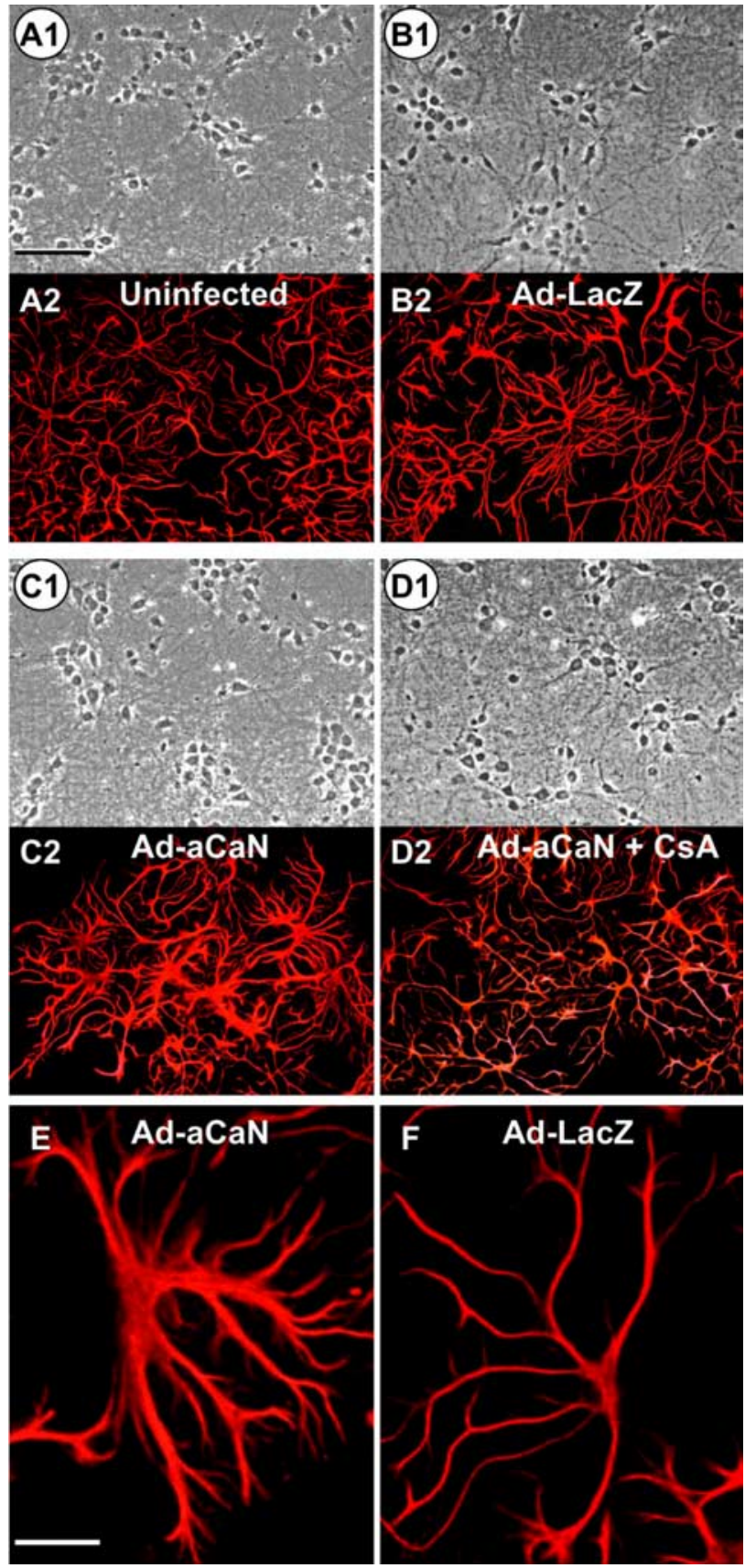

Figure 1. Active calcineurin induced hypertrophic morphological changes in astrocytes. Primary mixed hippocampal cultures were uninfected $(\boldsymbol{A})$, treated with $\mathrm{Ad}$-LacZ control virus $(\boldsymbol{B})$, and treated with $\mathrm{Ad}-\mathrm{a} C \mathrm{CN}$ to overexpress active calcineurin $(\boldsymbol{C})$ or with $\mathrm{Ad}-\mathrm{aCaN}$ together with cyclosporin A (CsA;5 $\mu \mathrm{M})$, a potent calcineurin inhibitor (D). A1-D1 are phase-contrast images illustrating neuronal morphology, whereas $\mathbf{A 2}-\mathbf{D 2}$ illustrate astrocyte morphology using a fluorescently labeled antibody to GFAP. Although astrocyte morphology was highly similar between uninfected and Ad-LacZ-infected cultures (A2 vs B2), Ad-aCaN-treated astrocytes (C2) were markedly different and were characterized by larger cell bodies and substantially thicker, more ramified processes. These $\mathrm{Ad}$-aCaN-associated changes in astrocyte morphology were prevented by coadministration of (SA (D2). Neuronal morphology was similar (A1-D1) across treatments. $\boldsymbol{E}, \boldsymbol{F}$, Higher-magnification images illustrating the differences in astrocyte size and morphology between Ad-aCaN (E) and Ad-LacZ control $(\boldsymbol{F})$ conditions. Scale bar: $\boldsymbol{A}-\boldsymbol{D}, 100 \mu \mathrm{m}$; $E, F, 25 \mu \mathrm{m}$.

study, insults (e.g., NMDA) that result in substantial neuronal death within $24 \mathrm{~h}$ do not cause similar profound changes in astrocyte morphology across the same time period (data not shown). Also, in the present study, the cocultured neurons exhib- 
ited no signs of selective damage or apoptosis in the Ad-aCaN-treated condition at $48 \mathrm{~h}$ after infection (Fig. 1, $C 1$ vs $A 1$ or $B 1)$. In addition, no upregulation in gene expression in the reported calcineurindependent caspase 3 apoptotic pathway was observed here, and, in fact, bad and bax were downregulated by active calcineurin (see below).

In addition, to confirm that the virally transferred calcineurin was taken up and expressed by astrocytes, we immunolabeled Ad-LacZ- and Ad-aCaN-treated cultures with an antibody against the $\mathrm{N}$ terminus of the calcineurin catalytic subunit (see Materials and Methods), which labels the full-length, endogenous calcineurin as well as the truncated, active calcineurin. Neurons were well labeled for endogenous calcineurin in both the Ad-LacZ and AdaCaN treatment conditions (Fig. $2 A, C, D, F)$. However, astrocytes in the Ad-LacZ condition exhibited little calcineurin labeling (Fig. $2 B, C$ ), reflecting very low levels of endogenous calcineurin in nonactivated astrocytes. Conversely, in the Ad-aCaN condition, the hypertrophic astrocytes (Fig. 2E) were labeled intensely for calcineurin, reflecting the uptake and expression of Ad-aCaN (Fig. 2F). Interestingly, neurons in the Ad-LacZ and AdaCaN treatment conditions showed similar intensities of calcineurin labeling (Fig. 2, $C$ vs $F$ ), suggesting that the Ad-aCaN construct was not taken up by neurons as readily as by astrocytes, an observation consistent with the preferential uptake of adenovirus by glial cells (Duale et al., 2005). Together, the results indicate that the effects of Ad-aCaN on astrocytes were mediated primarily by uptake and overexpression of calcineurin in astrocytes and by direct activation of intracellular astrocytic pathways regulating the activation response.

\section{Algorithm for identifying calcineurin-sensitive genes}

Testing the hypothesis that increased calcineurin activity is sufficient for triggering astrocyte pathways resulting in the activated phenotype, however, also requires testing whether the same genomic programs are activated in calcineurin-treated astrocytes and in activated astrocytes. Gene microarrays provide a new technology for evaluating the activity of thousands of genes simultaneously and are therefore particularly well suited to determine with high resolution the degree of similarity between two complex mosaics of cellular activation. In gene microarray studies, we tested the degree of overlap between calcineurin-sensitive and activation-associated genomic profiles. Lack of overlap (e.g., not greater than expected by chance) would provide a clear basis for rejecting the hypothesis that calcineurin is involved in astrocyte activation-related signaling cascades. These studies used rela-
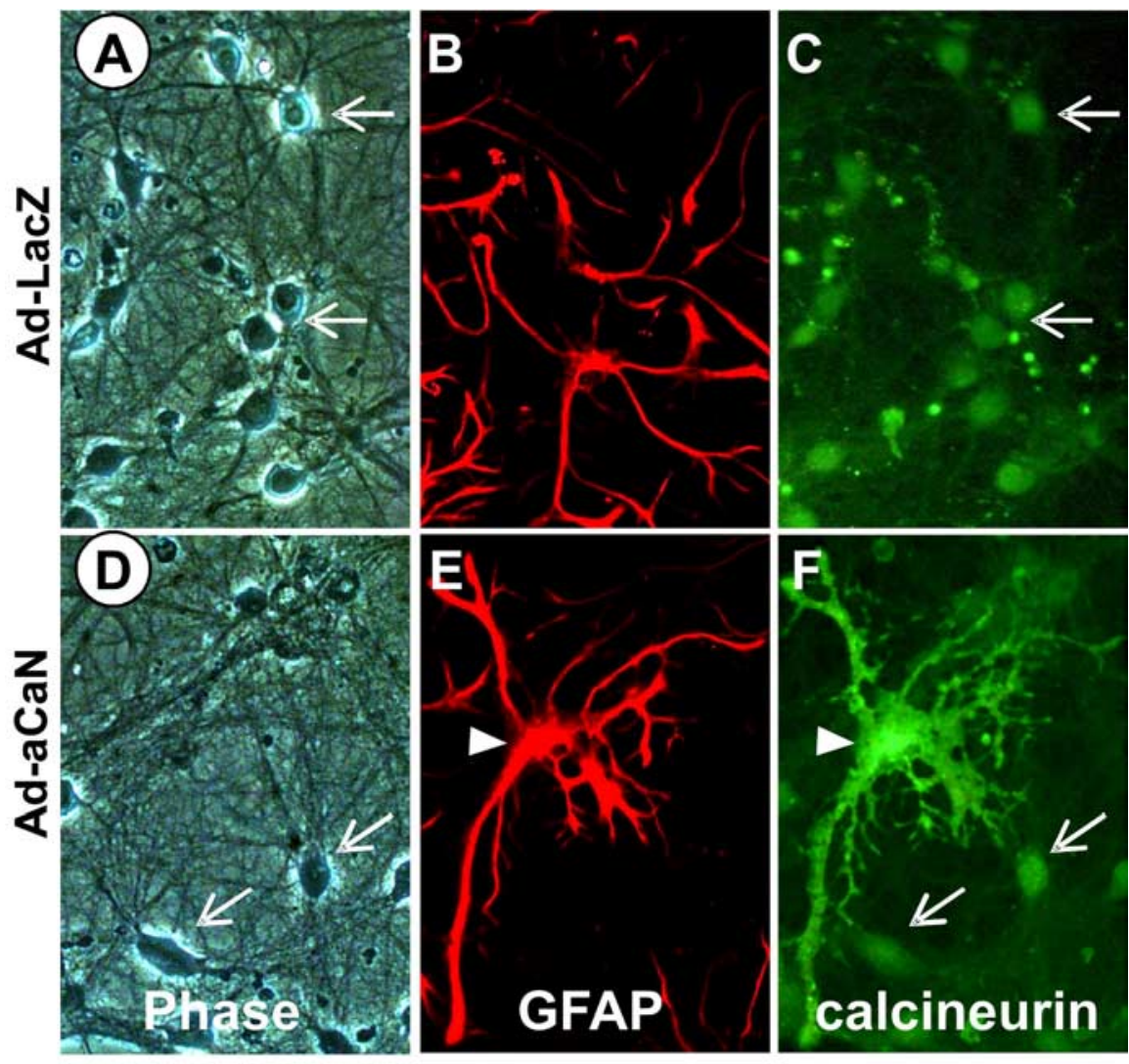

\section{G Uninfected Ad-LacZ Ad-aCaN}
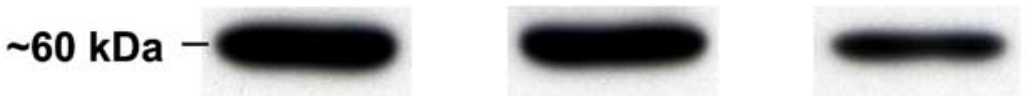

igure 2. Active calcineurin was intensely expressed in hypertrophied astrocytes in hippocampal cell cultures. Phase-contrast and immunofluorescent images of a single field from either an Ad-LacZ-treated culture $(\boldsymbol{A}-\boldsymbol{C})$ or an $\mathrm{Ad}$-aCaN-treated culture $(\boldsymbol{D}-\boldsymbol{F})$. Cultures were double labeled for the presence of calcineurin $(\boldsymbol{C}, \boldsymbol{F})$ and $\operatorname{GFAP}(\boldsymbol{B}, \boldsymbol{E}) . \boldsymbol{A}$ and $\boldsymbol{D}$ show the fields under phase contrast to highlight neurons. Note that, for both Ad-LacZ and Ad-aCaN treatments, endogenous calcineurin was well expressed intense in hypertrophied astrocytes in the $\mathrm{Ad}-\mathrm{aCaN}$ condition $(\boldsymbol{E}, \boldsymbol{F}$, arrowheads), illustrating uptake and expression of active calcineurin. $\mathbf{G}$, Representative Western blot showing the selective overexpression of the truncated $(\sim 45 \mathrm{kDa})$ active calcineurin fragment in the Ad-aCaN-treated cultures.

tively large and well powered sample sizes of independent replicates (microarrays) (see Materials and Methods), an approach that enables systematic statistical validation and provides estimates of expected false positives, reduces false negatives, and consequently lends substantial confidence to the results (Miller et al., 2001; Mirnics, 2001; Blalock, 2003; Blalock et al., 2003, 2004).

Paralleling the morphological studies above, cultures were infected at 12 DIV with Ad-aCaN or Ad-LacZ or were left uninfected. After $48 \mathrm{~h}$, the cultures were harvested and prepared for microarray analysis, using two culture dishes per microarray and seven to nine separate microarrays per condition (total of 23 separate microarray chips) (see Materials and Methods). 
Because the number of false positives expected from multiplecomparison error is directly proportional to the total number of transcript probes tested statistically (Miller et al., 2001; Blalock, 2003; Blalock et al., 2003), we reduced the total genes to be tested (from an initial 8799 transcript probe sets on the RG-U34A chip) by excluding genes rated "absent" in at least 19 chips (3460) or defined as expressed sequence tags (no gene symbol annotation in the Affymetrix database) (1936) as described previously (Blalock et al., 2003, 2004). The remaining gene probes (3403) were then each tested by one-way ANOVA across the three conditions (uninfected, $n=7$; Ad-LacZ, $n=7$; Ad-aCaN, $n=9$ ), and 1573 genes were found to differ significantly $(p \leq 0.05)$ across conditions. Expected false positives $(0.05 \times 3403)$ were 170 , and the maximum false discovery rate (expected false positives divided by total positives) was $170 / 1573$, or $\sim 0.11$. This is favorably low for a microarray study, likely reflecting good statistical power of these sample sizes (Blalock et al., 2003).

"Calcineurin-sensitive" genes among the ANOVA-significant set were identified by post hoc differences (Fisher's least significant difference; $p \leq 0.05$ ) between the Ad-aCaN group and the Ad-LacZ viral control group ( $n=719 ; 454$ upregulated, 265 downregulated by Ad-CaN) (supplemental Table 1, available at www.jneurosci.org as supplemental material). In addition, to reduce the impact of possible interactions between calcineurinsignaling pathways and pathways recruited specifically during adenoviral infection (regardless of the transgene expressed), we identified a smaller set of calcineurin-sensitive genes that also differed significantly from the uninfected control in the same direction ( $n=298$; 196 upregulated and 102 downregulated by Ad-aCaN) (this subpopulation is in bold in supplemental Table 1, available at www.jneurosci.org as supplemental material).

"Infection-sensitive" genes were defined as those that differed $(p<0.05)$ in the same direction in both adenoviral-treated conditions from the uninfected group but did not differ between the $\mathrm{Ad}-\mathrm{aCaN}$ and Ad-LacZ groups (i.e., were sensitive to general viral effects but insensitive to calcineurin activity) ( $n=535 ; 268$ upregulated, 267 downregulated) (supplemental Table 2, available at www.jneurosci.org as supplemental material). Expression differences for these genes were attributed to nonspecific effects of adenoviral-mediated infection.

\section{Calcineurin-sensitive genes overlap substantially with transcriptional profiles of astrocyte activation and brain aging}

A comprehensive review of astrocyte reactivity in 1997 listed $\sim 50$ specific antigens or families of proteins as documented markers of proximal activated astrocytes (Ridet et al., 1997). These fell mainly into functional categories of cytoskeletal filaments, growth factors/cytokines, recognition/adhesion molecules, enzymes, and some anomalously expressed neuronal markers.

In the present study, upregulated calcineurin-sensitive genes encoded $>50 \%$ of those different specific antigens (or of a related protein family member or receptor), including S100B, Vim, CNTF, PDGF, FGF receptor 2, IGF-2, annexin-1, proteoglycans, integrins, laminins, ICAM, tumor necrosis factor $\alpha$, and TGF $\beta$, among others (Ridet et al., 1997), and also encoded more recently identified markers as well [e.g., endothelin receptors, C/EBP (CCAAT/enhancer-binding protein), apolipoprotein E] (see supplemental Table 1 for names and full list, available at www. jneurosci.org as supplemental material). The reported antigen markers (Ridet et al., 1997) that were not induced here by calcineurin were generally low-abundance growth factors rated absent or not included on the chip. In addition, it is becoming increasingly apparent, as noted, that activated astrocytes constitute a major component of the neuroinflammatory response (Mrak and Griffin, 2001; Wyss-Coray and Mucke, 2002) and express numerous inflammatory markers and cytokines. Many of these were also upregulated by active calcineurin (supplemental Table 1, available at www.jneurosci.org as supplemental material). Thus, the overlap between calcineurin-sensitive and activation-associated markers is clearly exceedingly high.

In contrast, the substantially fewer genes downregulated by Ad-CaN appeared mostly unrelated to astrocyte markers and were instead related to energy and signaling pathways often associated with neuronal functions. The full sets of upregulated and downregulated Ad-aCaN-sensitive genes, with symbols and descriptions, are listed alphabetically in supplemental Table 1 (available at www.jneurosci.org as supplemental material).

We also applied a binomial analysis to obtain a quantitative probability for the degree of overlap between the set of significant calcineurin-sensitive genes in the current study (supplemental Table 1, available at www.jneurosci.org as supplemental material) and a published set of aging-dependent rat hippocampal genes identified previously in a well powered statistical study (Blalock et al., 2003) (supplemental Table 3, available at www.jneurosci.org as supplemental material). If calcineurin overexpression activates the set of genes that regulate astrocyte activation in aging, then many of the calcineurin-sensitive genes should also be found on the list of aging-dependent genes (which contains the set of aging-related astrocyte activation genes). However, it should be noted that, even with reasonable statistical power, false negatives are still considerable and, therefore, not all true-positive genes will be found significant at $p \leq 0.05$ in both independent studies (i.e., found to overlap).

Figure 3 shows that the two classes of overlap that were the same in direction (genes up with calcineurin/up with aging and genes down with calcineurin/down with aging) occurred far more frequently than expected by chance, whereas the two classes of overlap that were opposite in direction (genes up with calcineurin/down with aging and genes down with calcineurin/up with aging) occurred at or below chance levels. For up/up genes in particular (Fig. $3 B$ ), the probability of this degree of overlap occurring by chance alone was infinitesimally small $\left(p=2 e^{-13}\right)$. Examples of genes upregulated both by aging and by Ad-aCaN are shown in Figure $3 A$, and the full lists of overlapping genes are given in supplemental Table 3 (available at www.jneurosci.org as supplemental material). Thus, active calcineurin substantially recapitulated the gene profile related to astrocyte activation found in normally aging brain. Interestingly, many of these same genes and functional categories were also found in a recent microarray study to be elevated in incipient AD (Blalock et al., 2004), suggesting that upregulation of calcineurin-sensitive genes involved in astrocyte activation also may occur in early stage AD.

\section{Functional categorization by Expression Analysis Systematic Explorer and gene ontology}

To clarify potential functional implications of the gene sets generated for infection-sensitive and calcineurin-sensitive genes, these lists were processed using Expression Analysis Systematic Explorer software (EASE) (http://david.niaid.nih.gov/david/ ease.htm). EASE assigns genes to "biological process" categories of the hierarchical database maintained by the gene ontology (GO) consortium (http://www.geneontology.org) (Ashburner et al., 2000) and calculates an EASE score (a $p$ value derived from a modified Fisher's exact test) for each GO biological process category. The latter reflects the probability that any specific func- 
A

\begin{tabular}{|c|c|c|}
\hline Gene symbol & $\begin{array}{l}\text { Description } \\
\text { Deso oy aging }\end{array}$ & $\mathrm{p}$ value \\
\hline Bid3 & $\mathrm{BH} 3$ interacting domain 3 & $7.21 \mathrm{E}-03$ \\
\hline C3 & Complement component 3 & 3.69E-08 \\
\hline $\mathrm{Ca} 2$ & Carbonic anhydrase 2 & 3.90E-05 \\
\hline CD9 & CD9 cell surface glycoprotein & 1.66E-07 \\
\hline Cpt1a & Carnitine palmitoyltransferase 1 alpha & 8.20E-06 \\
\hline Cryab & Crystallin, alpha polypeptide 2 & $5.48 \mathrm{E}-09$ \\
\hline Csrp1 & cysteine rich protein 1 & 1.15E-08 \\
\hline Ctsl & Cathepsin L & 5.37E-06 \\
\hline Decr1 & 2,4-dienoyl CoA reductase 1 & $1.70 \mathrm{E}-11$ \\
\hline Dri42 & ER transmembrane protein Dri 42 & $9.16 \mathrm{E}-10$ \\
\hline Edg2 & Endoth. diff., lysophos. ac. GPCR, 2 & $1.29 \mathrm{E}-07$ \\
\hline Fcgrt & Fc receptor, IgG, alpha chain transporter & 2.77E-06 \\
\hline Fn1 & Fibronectin 1 & 1.35E-04 \\
\hline Ftl1 & Ferritin light chain 1 & 2.37E-06 \\
\hline Fxyd1 & FXYD domain-containing lon transport reg. 1 & 3.05E-04 \\
\hline Gp38 & Glycoprotein 38 & $3.99 \mathrm{E}-03$ \\
\hline Grn & Granulin & 2.46E-06 \\
\hline Gsta1 & Glutathione S-transferase, alpha 1 & $6.08 \mathrm{E}-08$ \\
\hline Gstp2 & Glutathione S-transferase pi 2 & 8.59E-06 \\
\hline IAG2 & Implantation-associated protein (IAG2) & 7.15E-05 \\
\hline Kai1/CD82 & Kangai 1 (suppression of tumorigenicity 6 ) & $1.44 \mathrm{E}-06$ \\
\hline Lamp2 & Lysosomal-associated membrane protein 2 & 4.11E-05 \\
\hline Lcat & Lecithin-cholesterol acyltransferase & $1.89 \mathrm{E}-07$ \\
\hline Litaf/Pig7 & LPS-induced TNF-alpha factor & 8.89E-05 \\
\hline Maob & Monoamine oxidase $\mathrm{B}$ & $6.62 \mathrm{E}-04$ \\
\hline Mgst1 & Microsomal glutathione S-transferase 1 & $1.55 \mathrm{E}-05$ \\
\hline Pdk2 & Pyruvate dehydrogenase kinase 2 & $2.34 \mathrm{E}-05$ \\
\hline Pld1 & Phoshpolipase D gene 1 & $1.41 \mathrm{E}-10$ \\
\hline Pmp22 & Peripheral myelin protein & $1.71 \mathrm{E}-11$ \\
\hline Prdx5 & Peroxiredoxin 5 & $9.39 E-08$ \\
\hline Psap & Prosaposin & $2.21 \mathrm{E}-02$ \\
\hline Ptgfr & Prostaglandin $\mathrm{F}$ receptor & 4.03E-08 \\
\hline RT1Aw2 & RT1 class lb gene & $6.06 \mathrm{E}-09$ \\
\hline RTS & MHC class I RT1 (RTS) & $6.29 \mathrm{E}-06$ \\
\hline S100a4 & S100 calcium-binding protein A4 & $1.42 \mathrm{E}-10$ \\
\hline S100b & S100 calcium-binding protein, beta & $2.45 \mathrm{E}-12$ \\
\hline Sdc4 & Ryudocan/syndecan 4 & 2.26E-02 \\
\hline Sts & Steroid sulfatase & $1.08 \mathrm{E}-03$ \\
\hline Tf & Transferrin & $6.40 \mathrm{E}-08$ \\
\hline Vim & vimentin & $2.55 \mathrm{E}-06$ \\
\hline
\end{tabular}

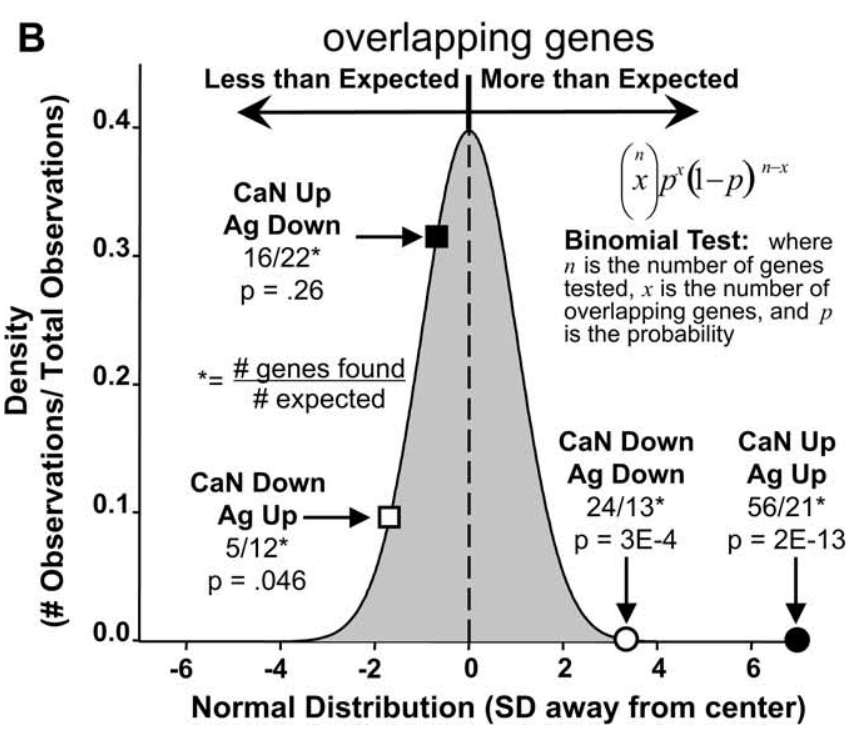

Table 1. G0 biological processes overrepresented by calcineurin-sensitive genes

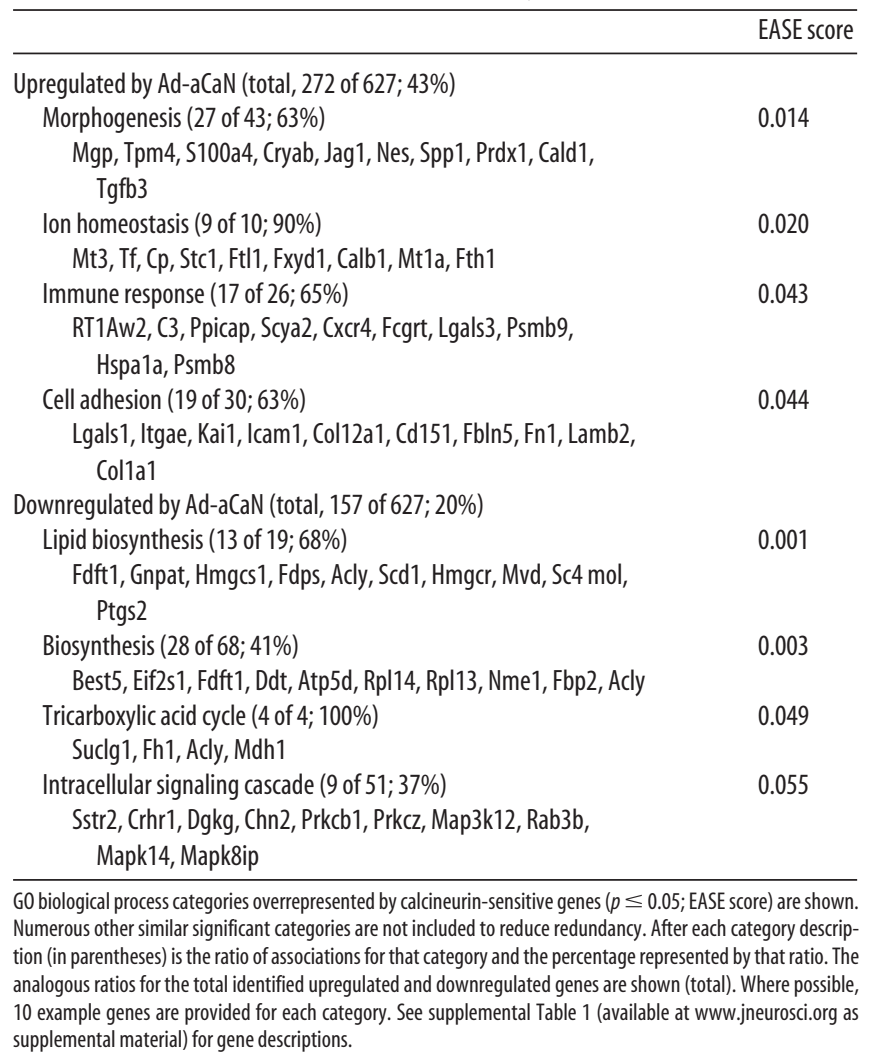

tional category is "overrepresented" by identified genes relative to the expected representation by identified genes for an average category. Because greater numbers of genes can strengthen analyses of coregulation, thereby providing important crossvalidation for altered pathways (Mirnics et al., 2001; Blalock et al., 2004), the larger set (supplemental Table 1, 719, available at www.jneurosci.org as supplemental material) of calcineurinsensitive genes was used for the pathway/category coregulation EASE analysis. However, the smaller set (boldface) was also subjected to the same analysis and yielded similar results (data not shown).

Table 1 shows some of the functional categories overrepresented by calcineurin-sensitive genes (EASE, $p<0.05$; multiple redundant categories have been omitted). The upregulated categories prominently reflected immune, defense, and stress responses associated with inflammation. In addition, upregulated categories included cell adhesion and morphogenesis, functions that are often associated with activation-related changes in astrocytes (Ridet et al., 1997). Examples of individual coregulated genes populating the overrepresented categories are also shown (Table 1), most of which are expressed in astrocytes. Essentially

$\leftarrow$

Figure 3. Microarray studies reveal that calcineurin overexpression recapitulates many of the transcriptional alterations seen in aging. $\boldsymbol{A}$, List of most genes that were upregulated by $\mathrm{Ad}-\mathrm{aCaN}$ in the present study and also by aging $(\mathrm{Ag})$ in Fischer 344 rats as reported by Blalock et al. (2003) (i.e., genes that change in the same direction with calcineurin activation and brain aging). $\boldsymbol{B}$, Binomial analysis (inset) revealed an overlap significantly greater than expected among genes found to agree in direction between the calcineurin $(\mathrm{CaN})$ and $\mathrm{Ag}$ studies (i.e., calcineurin Up/Ag Up, filled circle; calcineurin Down/Ag Down, open circle). Values for binomial probabilities are plotted on the $x$-axis (converted to SD). Their frequencies are plotted on the $y$-axis. Note the relative underrepresentation of genes found to disagree in direction (i.e., calcineurin Up/Ag Down, filled square; calcineurin Down/Ag Up, open square). 
Table 2. G0 biological processes overrepresented by infection-sensitive genes

\begin{tabular}{|c|c|}
\hline & EASE sco \\
\hline \multicolumn{2}{|l|}{ Upregulated by adenovirus (total, 178 of $907 ; 20 \%$ ) } \\
\hline Monovalent inorganic cation transport (17 of 38; 45\%) & 0.0001 \\
\hline Pigmentation ( 5 of $6 ; 83 \%)$ & 0.02 \\
\hline Behavior ( 6 of $11 ; 55 \%)$ & 0.04 \\
\hline \multicolumn{2}{|l|}{ Downregulated by adenovirus (total, 177 of $907 ; 20 \%$ ) } \\
\hline Nucleic acid metabolism (35 of 134; 26\%) & 0.02 \\
\hline Cell organization and biogenesis (18 of $59 ; 31 \%$ ) & 0.03 \\
\hline Transcription (24 of 87; 28\%) & 0.03 \\
\hline Development ( 27 of $104 ; 26 \%)$ & 0.04 \\
\hline Vesicle-mediated transport (10 of $28 ; 36 \%$ ) & 0.05 \\
\hline
\end{tabular}

GO biological process categories overrepresented by infection-sensitive genes ( $p \leq 0.05$; EASE score) are shown Numerous other similar significant categories are not included to reduce redundancy. After each category description (in parentheses) is the ratio of associations for that category and the percentage represented by that ratio. The analogous ratios for the total identified upregulated and downregulated genes are shown (total).

all of the calcineurin-sensitive upregulated categories were also identified in a study of aging brain in vivo (Blalock et al., 2003) and in a study of incipient $\mathrm{AD}$ (Blalock et al., 2004). There were fewer significant downregulated categories, primarily comprising biosynthesis and lipid synthesis genes.

The categories overrepresented by infection-sensitive genes (Table 2) were quite dissimilar from calcineurin categories and related primarily to ion transport functions (upregulated) and metabolism, transcription, and development (downregulated). Somewhat surprisingly (Lowenstein and Castro, 2003), no effects of adenoviral infection on inflammatory categories were observed.

\section{Statistical confidence in the microarray data}

The microarray results in this study appear highly reliable and validated, based on several factors. Each of thousands of genes was tested statistically, across adequately powered groups of independent samples (microarrays), thereby satisfying the same assumptions and criteria required in any statistical analysis of conventional single-variable data. In addition, because statistical power was adequate, the false discovery rate from multiplecomparison error was quite low ( $\sim 0.11$ is a worst-case estimate; when assuming no true positives, the actual value likely approaches $p=0.05$ ) (Blalock et al., 2003). In addition, the analysis of functional category representation in microarray studies, which lends substantial cross-validation to related genes in an overrepresented category (Mirnics et al., 2001), was determined statistically (EASE analysis). Finally, the binomial analysis of significant calcineurin-sensitive and significant brain aging-related genes (Fig. 3) shows a degree of overlap (and therefore validation) that would have a vanishingly small probability of occurring through chance or as a result of false positives.

\section{Immunocytochemical analyses of calcineurin in astrocytes of aging and Alzheimer's models}

The hypothesis of a causative role for calcineurin in the astrocyte activation process also predicts that calcineurin expression or

Figure 4. Calcineurin-immunoreactive astrocytes surround amyloid plaques in APP/PS1 Tg mice. $\boldsymbol{A}$, Immunofluorescent labeling of activated astrocytes in hippocampal area CA1 of a 13-month-old APP/PS1 mouse, using anti-GFAP primary antibody and a Texas Red-coupled secondary antibody. Note that these astrocytes are clustered around an unstained amyloid deposit (arrow). B, Amyloid plaques in area CA1 (stained with Congo Red; arrows) surrounded by activated astrocytes, which stained intensely for the presence of calcineurin. $\boldsymbol{C}$, Lowermagnification view of a cerebral cortical section stained for amyloid plaques (arrows) and calcineurin. Note that calcineurin staining is most intense in activated astrocytes immediately adjacent to amyloid deposits. $\boldsymbol{D}$, The upregulation of calcineurin in activated astrocytes was confirmed by double-labeling hippocampal sections for GFAP-positive astrocytes (red) and calcineurin (orange-yellow). Amyloid deposit appears purple (arrow).
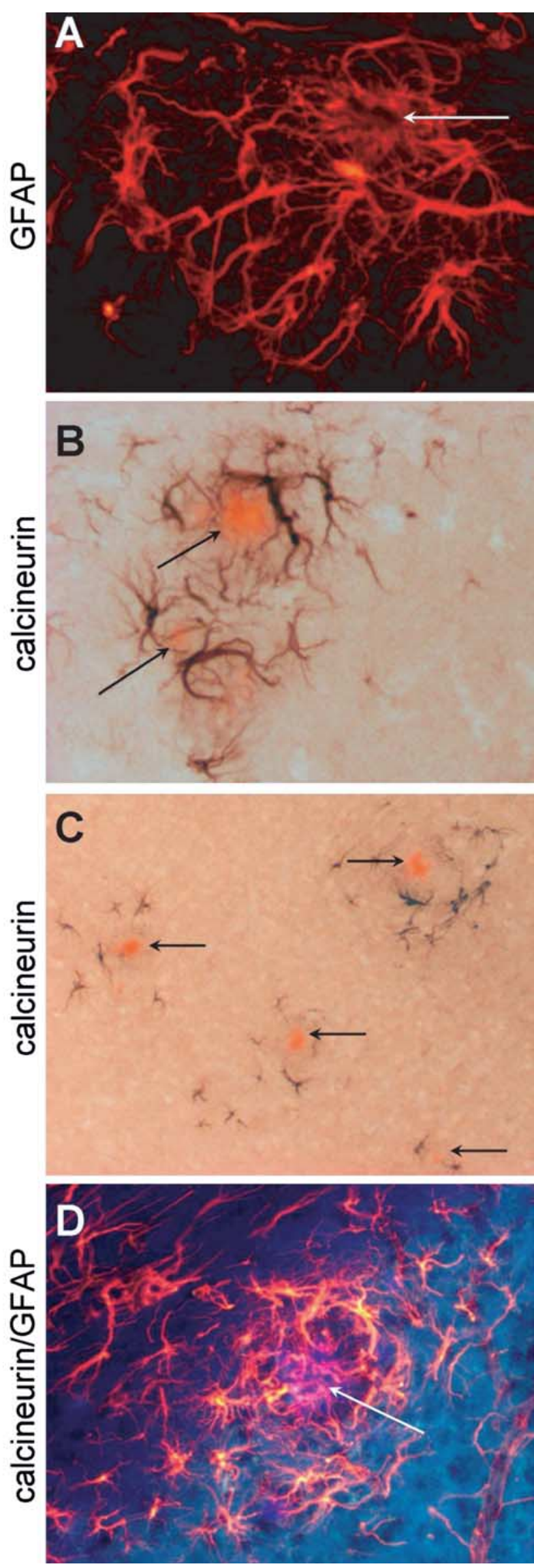
activity should be upregulated in activated astrocytes in the in vivo models. We therefore tested this prediction in Tg AD model and WT mice (see Materials and Methods) of three different ages (total, $n=9$ for each genotype). Alternate coronal brain sections were immunolabeled for calcineurin or for GFAP to identify astrocytes. Calcineurin-labeled sections were also treated with Congo Red to examine the colocalization of calcineurin with amyloid plaques.

As in other previous reports (Wisniewski and Wegiel, 1991; Van Eldik and Griffin, 1994; Matsuoka et al., 2001; Gordon et al., 2002), we observed GFAP-positive activated astrocytes clustered extensively around amyloid deposits/plaques in Tg mice (Fig. $4 A$ ). In addition, however, the activated astrocytes surrounding the amyloid plaques also were labeled intensely for calcineurin (Fig. $4 B, C$ ). The morphology and nearly exclusive association with plaques in $\mathrm{Tg}$ animals (Fig. 4C) clearly identified the calcineurin-positive cells as activated astrocytes. Moreover, analysis of double-labeled sections confirmed the colocalization of calcineurin and GFAP within the same cells (Fig. 4D). As with GFAP, the intensity of calcineurin labeling increased considerably with proximity to the amyloid plaque (Fig. $4 B-D$ ), indicating that calcineurin upregulation covaried with the degree of astrocyte activation.

As noted, the number of activated astrocytes also increases substantially with normal brain aging. Importantly, calcineurin upregulation in astrocytes paralleled this age dependence of activation both in Tg mice (Fig. 5A-C) and in WT mice (Fig. 5D-F). In WT mice, calcineurin upregulation was especially prominent in astrocytes throughout the hippocampus of animals 18-20 months of age (Fig. $5 F, G$ ). However, some astrocytes were calcineurin positive in middle-aged (12-13 months of age) WT mice (Fig. $5 E$ ), the age range in which the activated phenotype begins to appear (Landfield et al., 1980). In contrast, although calcineurin labeling was widespread throughout the apical dendrites of pyramidal neurons, particularly in region CA1 (Goto et al., 1986; Dawson et al., 1994), the neuronal labeling was considerably less intense than in activated astrocytes (Fig. 5). Moreover, in contrast to astrocyte labeling, calcineurin labeling of neurons did not increase (and may have decreased somewhat) with age. Thus, with aging, upregulation of calcineurin expression is selectively associated with activated astrocytes, regardless of whether the latter are related to amyloid deposition.

\section{Discussion}

\section{Evidence for a causative role}

The present study tested key predictions of the hypothesis that calcineurin upregulation in astrocytes plays a causative role in triggering the activation signaling cascade, particularly during aging and $\mathrm{AD}$. The results were highly consistent with these pre-
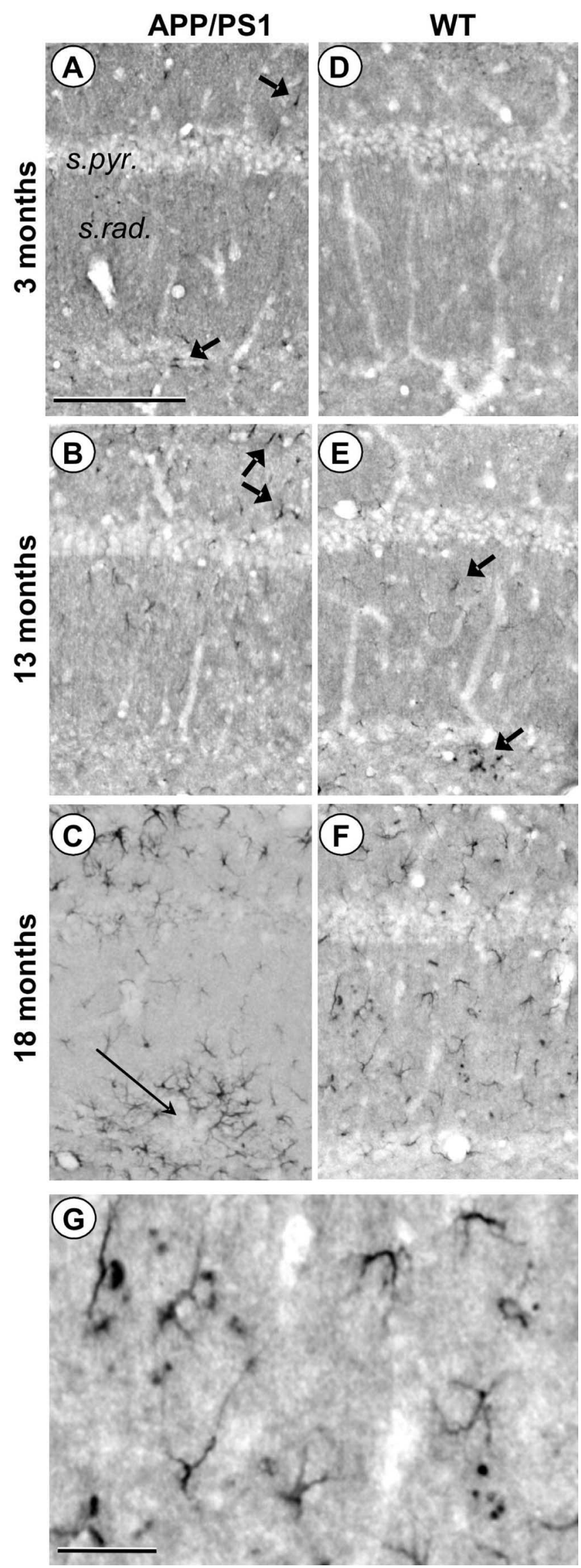

Figure 5. Calcineurin-immunoreactive astrocytes in hippocampal $C A 1$ increases as a function of age. Hippocampal sections taken from APP/PS1 (A-C) and $(57 \mathrm{BL} / 6 \mathrm{~J}$ WT mice $(\boldsymbol{D}-\boldsymbol{F})$ at 3,13 , and 18 months of age were immunostained for the presence of calcineurin. The occurrence of calcineurin-positive, activated astrocytes is relatively low until $\sim 13$ months of age, particularly in WT mice, at which time they begin to appear sporadically. By 18 months, activated astrocytes intensely immunoreactive for calcineurin are widely distributed throughout the hippocampus in WT mice and are clustered extensively around amyloid deposits in APP/PS1 mice. Note that neuropil staining for calcineurin may tend to decrease with age, primarily in APP/PS1 mice. G, Higher-magnification image of calcineurin-positive astrocytes in an 18month-old WT mouse. Short, thick arrows in $A, B$, and $E$ point to calcineurin-labeled astrocytes. The long, thin arrow in $C$ points to an unstained amyloid deposit. s. pyr., Stratum pyramidale; $S$. rad., stratum radiatum. Scale bars: $\mathbf{A}-\boldsymbol{F}, 200 \mu \mathrm{m} ; \mathbf{G}, 50 \mu \mathrm{m}$. 
dictions. Using an in vitro culture model to avoid confounds associated with application injury and immune system activation, which can occur with gene transfer in vivo (Lowenstein and Castro, 2003), overexpression of calcineurin induced a hypertrophic ramified structure (Figs. 1,2) that mimicked the in vivo activation phenotype (Figs. 4, 5) remarkably close.

Moreover, statistically based microarray analyses found that treatment with the Ad-aCaN construct in vitro induced essentially the full spectrum of gene expression changes across many individual genes and biological process categories (Fig. 3, Table 1) (supplemental Table 1, available at www.jneurosci.org as supplemental material) that has been previously observed with astrocyte activation in vivo (Eddleston and Mucke, 1993; Ridet et al., 1997; Mrak and Griffin, 2001; Labourdette and Eclancher, 2002; Wyss-Coray and Mucke, 2002; Blalock et al., 2003). Together, the results provide strong evidence for the conclusion that calcineurin overexpression in astrocytes recapitulates closely both the genomic profile and morphologic phenotype of the activation response of astrocytes.

Support for this hypothesis also requires evidence that calcineurin expression/activity is upregulated in activated astrocytes in vivo. In tests of this prediction, immunocytochemical studies revealed highly consistent association of calcineurin upregulation with activated astrocytes in aging/AD models. Calcineurin immunolabeling was extremely intense in activated astrocytes either in WT or Tg $\mathrm{AD}$-model mice but was virtually undetectable in nonactivated normal astrocytes (Figs. 4, 5), likely accounting for the conclusions of some previous studies (Goto et al., 1986; Dawson et al., 1994) that astrocytes contain little, if any, calcineurin. Thus, these findings also are strongly consistent with the hypothesis that calcineurin upregulation in astrocytes is a key intracellular signal for triggering the activation response in aging/AD models.

\section{A possible role for altered $\mathrm{Ca}^{2+}$ regulation in astrocytes and neurons}

Calcineurin expression was clearly not increased in neurons in our aging models (Fig. 5). However, considerable evidence indicates that $\mathrm{Ca}^{2+}$ regulation is altered in hippocampal neurons during normal aging or in Tg models of AD (Landfield et al., 1989; Disterhoft et al., 1994; Foster and Norris, 1997; Thibault et al., 1998, 2001; Leissring et al., 2000; Mattson et al., 2000; Toescu et al., 2004), which may lead to increased calcineurin activity, with or without a change in expression (Foster et al., 2001). An age-related increase in neuronal calcineurin activity is consistent with studies showing "aging-like" memory deficits in forebrainspecific, calcineurin-overexpressing mice (Mayford and Kandel, 1999; Mansuy, 2003). One possible source of $\mathrm{Ca}^{2+}$ dysregulation is the increased L-type $\mathrm{Ca}^{2+}$ channel activity that develops in hippocampal neurons with aging (Thibault and Landfield, 1996). This potential mechanism seems of particular interest in this context, because a similar upregulation of L-type channels occurs in astrocytes in regions of injury/ischemia (Westenbroek et al., 1998). In astrocytes, however, the increased L-type channel activity may provide signals for upregulation of calcineurin expression as well as activity. Clearly, extensive additional research will be needed to resolve these possibilities.

\section{Upstream role of calcineurin and positive-feedback mechanisms in astrocyte activation}

The results also indicate that calcineurin acts at the far upstream end of the intracellular activation cascade. That is, genes for most astrocyte-related growth factors/cytokines (e.g., TGF $\beta, \mathrm{S} 100 \mathrm{~B}$, cytokines, IGF-binding proteins, FGF2, and CNTF) or their receptors were upregulated by overexpression of active calcineurin (supplemental Table 1, available at www.jneurosci.org as supplemental material), suggesting that calcineurin acts upstream of these major regulatory factors. In addition, several calcineurin-sensitive genes, notably the igf and igfbp families and phosphatidylinositol 3-kinase, encode proteins that can sustain calcineurin-NFAT signaling by preventing NFAT deactivation (Musaro et al., 1999). These actions might act to establish a positive-feedback loop for further amplifying calcineurin activity in astrocytes. Somewhat similarly, calcineurin appears to increase L-type $\mathrm{Ca}^{2+}$ channel activity in hippocampal neurons, thereby perhaps also providing a mechanism for positivefeedback pathways that sustain calcineurin activity in neurons as well (Norris et al., 2002).

\section{Conclusions}

The present results indicate that calcineurin overexpression is sufficient for triggering the full activation cascade and phenotype, and that calcineurin upregulation is consistently present in activated astrocytes in aging and $\mathrm{AD}$-model animals. Consequently, the most parsimonious explanation appears to be that calcineurin upregulation generally is a key causative event that triggers astrocyte activation, at least in brain aging and $\mathrm{AD}$. However, definitive support for this conclusion will still require additional evidence, particularly from studies showing that calcineurin knockdown/knock-out approaches can prevent the development of astrocyte activation in these in situ models. Nonetheless, the present study provides the first evidence identifying calcineurin upregulation as a novel candidate for a master intracellular switch of the astrocyte activation cascade and, therefore, suggests that targeting calcineurin expression in astrocytes might represent a potentially important new therapeutic strategy against deleterious neuroinflammatory processes.

\section{References}

Ashburner M, Ball CA, Blake JA, Botstein D, Butler H, Cherry JM, Davis AP, Dolinski K, Dwight SS, Eppig JT, Harris MA, Hill DP, Issel-Tarver L, Kasarskis A, Lewis S, Matese JC, Richardson JE, Ringwald M, Rubin GM, Sherlock G (2000) Gene ontology: tool for the unification of biology The gene ontology consortium. Nat Genet 25:25-29.

Blalock EM (2003) Experimental design and data analysis. In: A beginner's guide to microarrays. (Blalock EM, ed), pp 179-241. Norwell, MA: Kluwer Academic.

Blalock EM, Chen KC, Sharrow K, Herman JP, Porter NM, Foster TC, Landfield PW (2003) Gene microarrays in hippocampal aging: statistical profiling identifies novel processes correlated with cognitive impairment J Neurosci 23:3807-3819.

Blalock EM, Geddes JW, Chen KC, Porter NM, Markesbery WR, Landfield PW (2004) Incipient Alzheimer's disease: microarray correlation analyses reveal major transcriptional and tumor suppressor responses. Proc Natl Acad Sci USA 101:2173-2178.

Borchelt DR, Ratovitski T, van Lare J, Lee MK, Gonzales V, Jenkins NA Copeland NG, Price DL, Sisodia SS (1997) Accelerated amyloid deposition in the brains of transgenic mice coexpressing mutant presenilin 1 and amyloid precursor proteins. Neuron 19:939-945.

Crabtree GR, Olson EN (2002) NFAT signaling: choreographing the social lives of cells. Cell [Suppl] 109:S67-S79.

Dawson TM, Steiner JP, Lyons WE, Fotuhi M, Blue M, Snyder SH (1994) The immunophilins, FK506 binding protein and cyclophilin, are discretely localized in the brain: relationship to calcineurin. Neuroscience 62:569-580.

Disterhoft JF, Moyer Jr JR, Thompson LT (1994) The calcium rationale in aging and Alzheimer's disease. Evidence from an animal model of normal aging. Ann NY Acad Sci 747:382-406.

Duale H, Kasparov S, Paton JF, Teschemacher AG (2005) Differences in transductional tropism of adenoviral and lentiviral vectors in the rat brainstem. Exp Physiol 90:71-78.

Eddleston M, Mucke L (1993) Molecular profile of reactive astrocytesimplications for their role in neurologic disease. Neuroscience 54:15-36.

Finch CE (2003) Neurons, glia, and plasticity in normal brain aging. Neurobiol Aging 24 [Suppl 1]:S123-S127, S131. 
Finch CE, Morgan T, Rozovsky I, Xie Z, Weindruch R, Prolla T (2002) Microglia and aging in the brain. In: Microglia in the degenerating and regenerating CNS (Streit WJ, ed), pp 275-305. New York: Springer.

Foster TC, Norris CM (1997) Age-associated changes in $\mathrm{Ca}^{2+}$-dependent processes: relation to hippocampal synaptic plasticity. Hippocampus 7:602-612.

Foster TC, Sharrow KM, Masse JR, Norris CM, Kumar A (2001) Calcineurin links $\mathrm{Ca}^{2+}$ dysregulation with brain aging. J Neurosci 21:4066-4073.

Gemma C, Mesches MH, Sepesi B, Choo K, Holmes DB, Bickford PC (2002) Diets enriched in foods with high antioxidant activity reverse age-induced decreases in cerebellar beta-adrenergic function and increases in proinflammatory cytokines. J Neurosci 22:6114-6120.

Gonzalez M, Ruggiero FP, Chang Q, Shi YJ, Rich MM, Kraner S, Balice-Gordon RJ (1999) Disruption of Trkb-mediated signaling induces disassembly of postsynaptic receptor clusters at neuromuscular junctions. Neuron 24:567-583.

Gordon MN, Holcomb LA, Jantzen PT, DiCarlo G, Wilcock D, Boyett KW, Connor K, Melachrino J, O'Callaghan JP, Morgan D (2002) Time course of the development of Alzheimer-like pathology in the doubly transgenic PS1+APP mouse. Exp Neurol 173:183-195.

Goto S, Matsukado Y, Mihara Y, Inoue N, Miyamoto E (1986) The distribution of calcineurin in rat brain by light and electron microscopic immunohistochemistry and enzyme-immunoassay. Brain Res 397:161-172.

Griffin WS, Stanley LC, Ling C, White L, MacLeod V, Perrot LJ, White III CL, Araoz C (1989) Brain interleukin 1 and S-100 immunoreactivity are elevated in Down syndrome and Alzheimer disease. Proc Natl Acad Sci USA 86:7611-7615.

Hashimoto Y, Perrino BA, Soderling TR (1990) Identification of an autoinhibitory domain in calcineurin. J Biol Chem 265:1924-1927.

Kadish I, Pradier L, van Groen T (2002) Transgenic mice expressing the human presenilin 1 gene demonstrate enhanced hippocampal reorganization following entorhinal cortex lesions. Brain Res Bull 57:587-594.

Labourdette G, Eclancher F (2002) Gliosis growth factors in the adult and aging brain. In: Neuroglia in the aging brain (de Vellis JS, ed), pp 157-178. Totowa, NJ: Humana.

Lam AG, Koppal T, Akama KT, Guo L, Craft JM, Samy B, Schavocky JP, Watterson DM, Van Eldik LJ (2001) Mechanism of glial activation by S100B: involvement of the transcription factor NFkappaB. Neurobiol Aging 22:765-772.

Landfield PW, Sundberg DK, Smith MS, Eldridge JC, Morris M (1980) Mammalian brain aging: theoretical implications of changes in brain and endocrine systems during mid- and late-life. Peptides [Suppl 1]:185-196.

Landfield PW, Campbell LW, Hao SY, Kerr DS (1989) Aging-related increases in voltage-sensitive, inactivating calcium currents in rat hippocampus. Implications for mechanisms of brain aging and Alzheimer's disease. Ann NY Acad Sci 568:95-105.

Lee CK, Weindruch R, Prolla TA (2000) Gene-expression profile of the ageing brain in mice. Nat Genet 25:294-297.

Leissring MA, Akbari Y, Fanger CM, Cahalan MD, Mattson MP, LaFerla FM (2000) Capacitative calcium entry deficits and elevated luminal calcium content in mutant presenilin-1 knockin mice. J Cell Biol 149:793-798.

Lowenstein PR, Castro MG (2003) Inflammation and adaptive immune responses to adenoviral vectors injected into the brain: peculiarities, mechanisms, and consequences. Gene Ther 10:946-954.

Manalan AS, Klee CB (1983) Activation of calcineurin by limited proteolysis. Proc Natl Acad Sci USA 80:4291-4295.

Mansuy IM (2003) Calcineurin in memory and bidirectional plasticity. Biochem Biophys Res Commun 311:1195-1208.

Matsuda T, Takuma K, Asano S, Kishida Y, Nakamura H, Mori K, Maeda S, Baba A (1998) Involvement of calcineurin in $\mathrm{Ca}^{2+}$ paradox-like injury of cultured rat astrocytes. J Neurochem 70:2004-2011.

Matsuoka Y, Picciano M, Malester B, LaFrancois J, Zehr C, Daeschner JM, Olschowka JA, Fonseca MI, O’Banion MK, Tenner AJ, Lemere CA, Duff K (2001) Inflammatory responses to amyloidosis in a transgenic mouse model of Alzheimer's disease. Am J Pathol 158:1345-1354.

Mattson MP, LaFerla FM, Chan SL, Leissring MA, Shepel PN, Geiger JD (2000) Calcium signaling in the ER: its role in neuronal plasticity and neurodegenerative disorders. Trends Neurosci 23:222-229.

Mayford M, Kandel ER (1999) Genetic approaches to memory storage. Trends Genet 15:463-470.

Miller RA, Galecki A, Shmookler-Reis RJ (2001) Interpretation, design, and analysis of gene array expression experiments. J Gerontol A Biol Sci Med Sci 56:B52-B57.

Mirnics K (2001) Microarrays in brain research: the good, the bad and the ugly. Nat Rev Neurosci 2:444-447.
Mirnics K, Middleton FA, Lewis DA, Levitt P (2001) Analysis of complex brain disorders with gene expression microarrays: schizophrenia as a disease of the synapse. Trends Neurosci 24:479-486.

Molkentin JD, Lu JR, Antos CL, Markham B, Richardson J, Robbins J, Grant SR, Olson EN (1998) A calcineurin-dependent transcriptional pathway for cardiac hypertrophy. Cell 93:215-228.

Mrak RE, Griffin WS (2001) Interleukin-1, neuroinflammation, and Alzheimer's disease. Neurobiol Aging 22:903-908.

Mrak RE, Griffin ST, Graham DI (1997) Aging-associated changes in human brain. J Neuropathol Exp Neurol 56:1269-1275.

Musaro A, McCullagh KJ, Naya FJ, Olson EN, Rosenthal N (1999) IGF-1 induces skeletal myocyte hypertrophy through calcineurin in association with GATA-2 and NF-AIc1. Nature 400:581-585.

Norris CM, Blalock EM, Chen KC, Porter NM, Landfield PW (2002) Calcineurin enhances L-type $\mathrm{Ca}^{2+}$ channel activity in hippocampal neurons: increased effect with age in culture. Neuroscience 110:213-225.

Porter NM, Thibault O, Thibault V, Chen KC, Landfield PW (1997) Calcium channel density and hippocampal cell death with age in long-term culture. J Neurosci 17:5629-5639.

Pyrzynska B, Lis A, Mosieniak G, Kaminska B (2001) Cyclosporin A-sensitive signaling pathway involving calcineurin regulates survival of reactive astrocytes. Neurochem Int 38:409-415.

Reuter A, Mi J, Sehrsam I, Ludolph AC, Volkel H (2001) A novel calcineurin splice variant that modifies calcineurin activity. Eur J Biochem 268:5955-5960.

Ridet JL, Malhotra SK, Privat A, Gage FH (1997) Reactive astrocytes: cellular and molecular cues to biological function. Trends Neurosci 20:570-577.

Rogers J, Webster S, Lue LF, Brachova L, Civin WH, Emmerling M, Shivers B, Walker D, McGeer P (1996) Inflammation and Alzheimer's disease pathogenesis. Neurobiol Aging 17:681-686.

Sheng JG, Ito K, Skinner RD, Mrak RE, Rovnaghi CR, Van Eldik LJ, Griffin WS (1996) In vivo and in vitro evidence supporting a role for the inflammatory cytokine interleukin-1 as a driving force in Alzheimer pathogenesis. Neurobiol Aging 17:761-766.

Thibault O, Landfield PW (1996) Increase in single L-type calcium channels in hippocampal neurons during aging. Science 272:1017-1020.

Thibault O, Porter NM, Chen KC, Blalock EM, Kaminker PG, Clodfelter GV, Brewer LD, Landfield PW (1998) Calcium dysregulation in neuronal aging and Alzheimer's disease: history and new directions. Cell Calcium 24:417-433.

Thibault O, Hadley R, Landfield PW (2001) Elevated postsynaptic $\left[\mathrm{Ca}^{2+}\right] \mathrm{i}$ and L-type calcium channel activity in aged hippocampal neurons: relationship to impaired synaptic plasticity. J Neurosci 21:9744-9756.

Toescu EC, Verkhratsky A, Landfield PW (2004) $\mathrm{Ca}^{2+}$ regulation and gene expression in normal brain aging. Trends Neurosci 27:614-620.

Van Eldik LJ, Griffin WS (1994) S100 beta expression in Alzheimer's disease: relation to neuropathology in brain regions. Biochim Biophys Acta 1223:398-403.

Vaughan DW, Peters A (1974) Neuroglial cells in the cerebral cortex of rats from young adulthood to old age: an electron microscope study. J Neurocytol 3:405-429.

Wang HG, Pathan N, Ethell IM, Krajewski S, Yamaguchi Y, Shibasaki F, McKeon F, Bobo T, Franke TF, Reed JC (1999) $\mathrm{Ca}^{2+}$-induced apoptosis through calcineurin dephosphorylation of BAD. Science 284:339-343.

Wenk GL (2003) Neuropathologic changes in Alzheimer's disease. J Clin Psychiatry 64 [Suppl 9]:7-10.

Westenbroek RE, Bausch SB, Lin RC, Franck JE, Noebels JL, Catterall WA (1998) Upregulation of L-type $\mathrm{Ca}^{2+}$ channels in reactive astrocytes after brain injury, hypomyelination, and ischemia. J Neurosci 18:2321-2334.

Wisniewski HM, Terry RD (1973) Morphology of the aging brain, human and animal. Prog Brain Res 40:167-186.

Wisniewski HM, Wegiel J (1991) Spatial relationships between astrocytes and classical plaque components. Neurobiol Aging 12:593-600.

Wyss-Coray T, Mucke L (2002) Inflammation in neurodegenerative disease- a double-edged sword. Neuron 35:419-432.

Wyss-Coray T, Feng L, Masliah E, Ruppe MD, Lee HS, Toggas SM, Rockenstein EM, Mucke L (1995) Increased central nervous system production of extracellular matrix components and development of hydrocephalus in transgenic mice overexpressing transforming growth factor-beta 1. Am J Pathol 147:53-67.

Xie C, Markesbery WR, Lovell MA (2000) Survival of hippocampal and cortical neurons in a mixture of MEM+ and B27-supplemented neurobasal medium. Free Radic Biol Med 28:665-672. 